\title{
Classifying high-risk versus very high-risk prostate cancer: is it relevant to outcomes of conformal radiotherapy and androgen deprivation?
}

Akram Saad ${ }^{1 \dagger}$, Jeffrey Goldstein ${ }^{1 \dagger}$, Yaacov R. Lawrence ${ }^{1}$, Benjamin Spieler ${ }^{1}$, Raya Leibowitz-Amit ${ }^{2}$, Raanan Berger ${ }^{2}$, Tima Davidson ${ }^{3}$, Damien Urban², Lev Tsang ${ }^{1}$, Dror Alezra', ${ }^{1}$ llana Weiss ${ }^{1}$ and Zvi Symon ${ }^{1 *+}$

\begin{abstract}
Objective: To evaluate outcomes in prostate cancer patients classified as high-risk (HR) or very high-risk (VHR) who were treated with conformal radiation therapy (CRT) and androgen deprivation therapy (ADT).

Methods: Between 11/2001 and 3/2012, 203 patients with HR disease received CRT to the prostate (78-82 Gy) and pelvic lymph nodes (46-50 Gy) with ADT (6 m-2 years). Median follow-up was 50 months (12 m-142 m). Biochemical failure was defined according to Phoenix definition. Imaging studies were used to identify local, regional or metastatic failure. Four different VHR/HR groupings were formed using the 2014 and revised 2015 NCCN guidelines. Differences were examined using Kaplan Meier (KM) estimates with log rank test and uni- and multivariate Cox regression analysis (MVA).

Results: Failure occurred in 30/203 patients (15\%). Median time to failure was $30 \mathrm{~m}$ (4 m-76 m). KM estimate of 4 year biochemical disease free survival (b-DFS) for the entire cohort was $87 \%$ (95\%Cl: 82-92\%). Four year KM survival estimates for b-DFS, PCSS and OS were comparable for each NCCN subgroup. On univariate analysis, the NCCN subgroups were not predictive of b-DFS at 4 years, however, DMFS was worse for both VHR subgroups $(p=.03$ and .01$)$ respectively. Cox univariate analysis was also significant for: PSA $\geq 40 \mathrm{ng} / \mathrm{ml} p=0.001$; clinical stages T2c $p=.004$, T3b $p=.02$ and $>4$ cores with Gleason score 8-10 $p<.03$. On MVA, only PSA $\geq 40 \mathrm{ng} / \mathrm{ml}$ was predictive for b-DFS or MFS at 4 years (HR: 3.75 and $3.25, p<0.005$ ).

Conclusion: Patients with HR and VHR disease treated with CRT and ADT had good outcomes. Stratification into $H R$ and VHR sub-groups provided no predictive value. Only PSA $\geq 40 \mathrm{ng} / \mathrm{ml}$ predicted poor outcomes on MVA. Distant failure was dominant and local recurrence rare, suggesting that improved systemic treatment rather than intensification of local therapy is needed.
\end{abstract}

Summary: Patients with high-risk prostate cancer are most often treated with conformal dose escalated radiation therapy with androgen deprivation. Stratification into high versus very high-risk subgroups using 2014 or revised 2015 National Comprehensive Cancer Network (NCCN) criteria did not impact treatment outcomes. Only Prostate Serum Antigen (PSA) $\geq 40 \mathrm{ng} / \mathrm{ml}$ was predictive of poor prognosis. Distant failure was dominant and local recurrence uncommon which challenges the notion that intensification of local therapy will further improve outcomes in patients with high-risk disease.

\footnotetext{
* Correspondence: Zvi.Symon@sheba.health.gov.il

${ }^{\dagger}$ Equal contributors

${ }^{1}$ Departments of Radiation Oncology, Chaim Sheba Medical Center, Tel Aviv

University Sackler School of Medicine, Tel Hashomer, 52621 Ramat Gan, Israel

Full list of author information is available at the end of the article
} 


\section{Introduction}

Physicians and patients, when asked about therapy for localized prostate cancer often look to the National Comprehensive Cancer Network (NCCN) guidelines to provide guidance for selection between different treatment options [1]. Since patients with high-risk (HR) disease have a heterogeneous prognosis, this group has been further subdivided to separate patients thought to have the worst prognosis into the very high-risk (VHR) category [1].

Radiation therapy (RT) has long been considered the primary treatment modality for patients with HR disease and is the only treatment considered by the National Comprehensive Cancer Network (NCCN) to have sufficient evidence to support a Category 1 treatment recommendation [1]. Despite the NCCN treatment recommendations based on improved outcomes for HR patients treated with high dose conformal radiation therapy (CRT) and androgen deprivation therapy (ADT), there is growing interest in the use of radical prostatectomy (RP) for patients with HR disease $[2,3]$. Justifications given for considering surgery are high rates of local and systemic failure associated with the use of RT as well as reported good outcomes associated with the use of surgery [2,3].

Sundi et al. defined a VHR group with adverse prognostic factors predictive for poor outcome following surgery and suggested the need for multimodal therapy to improve outcomes $[4,5]$. In consideration of these findings, the 2014 NCCN guidelines were revised and added the presence of primary Gleason grade 5 or $\geq 5$ cores with Gleason score 8-10 as new criteria for inclusion into the VHR group [1]. While relevant for surgical outcomes, the predictive value of the HR/VHR grouping has not been assessed in patients treated with current CRT techniques [6]. Recently, Narang et al. showed inferior outcomes in the VHR versus HR group in a cohort of patients treated with RT and ADT from 1993 through 2006. However, this retrospective study was limited by use of radiation techniques, treatment volumes, dose, and use of ADT that do not reflect current therapeutic approaches [6].

We reviewed treatment outcomes in a cohort of patients with HR disease treated with high dose CRT and ADT to determine if local recurrence (LR) or metastatic disease was predominant. Patients were stratified according to the original and revised NCCN guidelines for HR/VHR groups. The value of this classification system to provide prognostic guidance and improved treatment recommendations for patients with HR disease was assessed.

\section{Methods}

\section{Patients}

The radiation oncology prostate cancer database of 509 patients entered between November 2001 and March
2012 was reviewed following approval of the hospital ethics committee. Patients meeting NCCN criteria for HR or VHR disease $(n=203)$ who were treated with CRT were identified. Demographic information, clinical stage, PSA, Gleason grade and score, number and percentage of biopsy cores involved with tumor, use of ADT, and early and late treatment toxicity data were extracted from the electronic medical record. Treatment technique, radiation dose, fraction schedule, target volume and use of image guidance were obtained from the treatment planning system.

The characteristics and treatments of these $203 \mathrm{HR}$ patients are listed in Table 1 . Median age was 74 years (range 56 years-89 years). Gleason scores were $>7$ in 143 patients and $\leq 7$ in 60 patients. Primary Gleason grade 5 and Gleason score $8-10$ in $\geq 5$ cores occurred in 17 patients and 82 patients respectively. Median PSA was $15.1 \mathrm{ng} / \mathrm{ml}$ (range: $1.4 \mathrm{ng} / \mathrm{ml}-449 \mathrm{ng} / \mathrm{ml}$ ). PSA level was $\geq 40 \mathrm{ng} / \mathrm{ml}$ in 33 patients and $<40 \mathrm{ng} / \mathrm{ml}$ in 170 patients. Clinical stage was $\leq \mathrm{T} 2 \mathrm{~b}$ in 85 patients, T2c in 19 patients, T3a in 62 patients and $\geq \mathrm{T} 3 \mathrm{~b}$ in 37 patients. Almost half of the cohort had $\geq$ stage T3 disease.

\section{NCCN Risk group stratification}

The study population included all patients with clinical stage $\geq \mathrm{T} 3 \mathrm{a}$, or Gleason score $\geq 8$, or PSA $>20 \mathrm{ng} / \mathrm{ml}$. These patients were sorted according to the NCCN definitions of HR and VHR using the original or revised criteria for VHR: $(\geq \mathrm{T} 3 \mathrm{~B})$ or $(\geq \mathrm{T} 3 \mathrm{~b}$ or primary Gleason 5 or $\geq 5$ cores with Gleason $8-10$ ). Since patients with $\geq 2$ HR factors present may be considered as either HR or VHR, and this upstaging is not applied universally, the original and revised NCCN groups were each considered \pm upstaging for patients with $\geq 2 \mathrm{HR}$ factors. The 4 different HR/ VHR groupings created using NCCN criteria were compared.

\section{Planning and treatment guidelines}

All patients received high dose CRT to the prostate and seminal vesicles, pelvic lymph node RT (PLNRT) and ADT. Contouring and planning guidelines evolved over time and guidelines in current use are described below.

Prostate and Seminal Vesicles: The prostate was contoured on axial images from the treatment planning CT scan. The entire seminal vesicles were contoured separately. The prostate and seminal vesicles were combined to create the CTV and then expanded $1 \mathrm{~cm}$ in all directions except for $0.7 \mathrm{~cm}$ posteriorly to create the PTV. The PTV and CTV were planned to 95 and $98 \%$ of the prescribed dose respectively. Three treatment protocols were used for treatment: From 2001 to 2009, 30 patients received $3 \mathrm{D}$ CRT to $78 \mathrm{~Gy}-82 \mathrm{~Gy}$ at $2 \mathrm{~Gy} / \mathrm{fx}$; from 2004 to 2011,72 patients received IMRT to $78 \mathrm{~Gy}-82 \mathrm{~Gy}$ at $2 \mathrm{~Gy} / \mathrm{fx}$, and from 2010 to 2012, 101 patients received 
Table 1 Patient characteristics

\begin{tabular}{|c|c|c|c|c|}
\hline \multirow[t]{2}{*}{ Parameter } & \multicolumn{2}{|l|}{ All patients } & \multicolumn{2}{|c|}{$\begin{array}{l}\text { Patient's with } \\
\text { biochemical failure }\end{array}$} \\
\hline & $N=203$ & $\%$ & $N=30$ & $\%$ \\
\hline \multicolumn{5}{|l|}{ Age (year) } \\
\hline Median (range) & 75 (56-89) & - & 74.5 (56-86) & - \\
\hline \multicolumn{5}{|l|}{ Clinical stage } \\
\hline $\mathrm{T} 1-\mathrm{T} 2 \mathrm{a}$ & 39 & 19.2 & 3 & 10 \\
\hline$T 2 b-c$ & 65 & 32 & 10 & 33.3 \\
\hline T3a & 62 & 30.5 & 9 & 30 \\
\hline T3b-T4 & 37 & 18.3 & 8 & 26.7 \\
\hline \multicolumn{5}{|l|}{ Gleason score } \\
\hline$\leq 6$ & 15 & 7.4 & 1 & 3.3 \\
\hline 7 & 45 & 21.2 & 8 & 26.7 \\
\hline $8-10$ & 143 & 70.4 & 21 & 70 \\
\hline \multicolumn{5}{|l|}{ PSA } \\
\hline Median (range) & $16(1.4-449)$ & - & $22.7(1.4-449)$ & - \\
\hline$<10$ & 71 & 35 & 8 & 26.66 \\
\hline $10-20$ & 48 & 23.6 & 6 & 20 \\
\hline $20.1-39.9$ & 51 & 25.1 & 5 & 16.66 \\
\hline$\geq 40$ & 33 & 16.3 & 11 & 36.66 \\
\hline \multicolumn{5}{|c|}{$>4$ cores positive with Gleason 8-10 } \\
\hline$\leq 4$ & 109 & 53.7 & 12 & 40 \\
\hline$>4$ & 82 & 40.4 & 17 & 56.7 \\
\hline Unknown & 12 & 5.9 & 1 & 3.3 \\
\hline \multicolumn{5}{|c|}{ Primary Gleason pattern } \\
\hline$<5$ & 186 & 91.6 & 25 & 83.3 \\
\hline 5 & 17 & 8.4 & 5 & 16.7 \\
\hline \multicolumn{5}{|l|}{ NCCN risk group } \\
\hline High risk & 100 & 49.3 & 11 & 36.7 \\
\hline $\mathrm{VHR}$ & 103 & 50.7 & 19 & 63.3 \\
\hline \multicolumn{5}{|l|}{ RT technique } \\
\hline $3 \mathrm{D}$ & 29 & 14.3 & 6 & 20 \\
\hline IMRT & 60 & 29.6 & 11 & 36.7 \\
\hline VMAT & 114 & 56.1 & 13 & 43.3 \\
\hline \multicolumn{5}{|l|}{ ADT use } \\
\hline Yes & 197 & 97 & 28 & 93.3 \\
\hline No & 6 & 3 & 2 & 6.66 \\
\hline Duration $\leq 6 \mathrm{mo}$ & 14 & 6.9 & 0 & 0 \\
\hline Duration 6-24 mo & 9 & 4.4 & 2 & 6.66 \\
\hline Duration $\geq 24 \mathrm{mo}$ & 174 & 85.7 & 26 & 86.66 \\
\hline \multicolumn{5}{|l|}{ Prostate radiation dose } \\
\hline$<78$ Gy 2 Gy/fx. & 5 & 2.5 & 1 & 3.3 \\
\hline 78-82 Gy 2 Gy/fx & 97 & 47.8 & 18 & 60 \\
\hline 73.6 Gy 2.3 Gy/fx & 101 & 49.7 & 11 & 36.7 \\
\hline
\end{tabular}

Table 1 Patient characteristics (Continued)

\begin{tabular}{lllll}
\hline $\begin{array}{llll}\text { Pelvic lymph node RT } \\
\text { Yes }\end{array}$ & 201 & 99 & 30 & 100 \\
No & 2 & 1 & 0 & 0 \\
46 Gy & 88 & 43.3 & 16 & 53.3 \\
54.4 Gy & 113 & 55.7 & 14 & 46.7 \\
\hline
\end{tabular}

VMAT and hypo-fractionation to $73.6 \mathrm{~Gy}$ at $2.3 \mathrm{~Gy} / \mathrm{fx}$ (80Gy 2 gy/eq., $\sigma / \beta=1.5$ ). Image guided radiation therapy (IGRT) was introduced into the clinic in 2009 and daily on-line correction was performed daily for all patients [7].

\section{PLNRT}

Pelvic lymph nodes were identified by contouring and expanding by $7 \mathrm{~mm}$ the distal common iliac vessels and external iliac vessels from L5/S1 to the femoral head and symphysis pubis, carving out bowel, bladder and bone. PLNRT was given at $46 \mathrm{~Gy}$ at $2 \mathrm{~Gy} / \mathrm{fx}$. After 2011, PLNRT was given at $54.4 \mathrm{~Gy}$ at $1.7 \mathrm{~Gy} / \mathrm{fx}$ (50Gy 2 Gy/eq, $\alpha / \beta=1.5$ ). All but 2 patients received PLNRT.

\section{Organs at risk}

The bladder, rectum from anus to sacral promontory, loops of bowel and femoral heads were contoured. Small bowel dose was limited to 54 Gy with no more than 2 cc receiving 50 Gy. Rectal dose was limited to $\mathrm{V} 75<15 \%, \mathrm{~V} 70<25 \%$ and $\mathrm{V} 50<50 \%$. Bladder dose was V80 $<15 \%$, V75 25\%, V65 $<65 \%$ and femoral head dose was $<40 \mathrm{~Gy}$.

$A D T$

ADT was prescribed for 6 months- 3 years. ADT duration: $\leq 6$ months $n=14$ (7\%); $>6$ months- $<24$ months $n=9(4.4 \%) ; \geq 24$ months $n=174(86 \%)$. Six patients $(3 \%)$ received no ADT and 1 of these did not receive PLNRT.

\section{Follow up}

Median follow-up for the entire cohort was 50 months (m) (range: $12 \mathrm{~m}-142 \mathrm{~m}$ ). Follow-up evaluations following CRT were performed at intervals of $6 \mathrm{~m}$ to 1 year. Patients who did not appear for follow-up were contacted telephonically and PSA results were obtained from the electronic medical record.

Biochemical recurrence (BR): When BR was detected, patients underwent diagnostic evaluation with bone scan and CT scans. If the site of recurrence was not identified, patients were offered imaging with choline PET-CT or endorectal MRI (e-MRI), [8]. ADT was not started unless metastatic disease was found. Patients with local, regional, or oligo-metastatic recurrence were offered focal radiation therapy with short term ADT at the discretion of the treating physician. 


\section{Endpoints}

Endpoints used include biochemical disease free survival (b-DFS), (Phoenix definition) [9], distant metastasis free survival (DMFS), prostate cancer specific survival (PCSS) and overall survival (OS). Toxicity and side effects were recorded using CTCAE version 4 [10].

\section{Statistics}

Statistical analysis was performed using STATA. Continuous and categorical variables were compared using a two-tailed Students t-test or Chi-squared test respectively. The Kaplan-Meier (KM) method was used to calculate probability of survival and toxicity. Cox univariate analysis was conducted using log-rank tests and univariate predictors with a $p$-value $<0.2$ were further considered using a Cox multivariate proportional hazards model (MVA) to identify predictors of gastrointestinal (GI) or genitourinary (GU) toxicity and survival. $P$ values $\leq .05$ were considered significant.

\section{Results}

Failure occurred in 30/203(15\%) patients. Median time to failure was $30 \mathrm{~m}$ (range: $4 \mathrm{~m}-76 \mathrm{~m}$ ). Failures were classified as BR only $(n=4)$, local $(n=1)$ or metastatic $(n=25)$. Table 2 lists the sites of failure. In 8 patients who were initially classified as BR, the use of choline PET-CT imaging showed the location and extent of recurrence. Prostate cancer specific mortality was recorded in 4 patients. Eleven deaths were unrelated to prostate cancer.

Four different NCCN HR/VHR groupings were evaluated. Patients shifted from the HR group to the VHR group as definitions evolved and additional risk features were included (Table 3). The size of the VHR group increased from 18 to $68 \%$ of the patients and HR group decreased from 82 to $32 \%$.

KM estimate of 4 year b-DFS for the entire cohort was 87\% (95\%CI: 82-92\%). The 4 year KM survival estimates for b-DFS, CSS and OS were comparable for each of the NCCN subgroups (Table 3) and this was confirmed by Cox regression. On univariate analysis, the NCCN subgroups were not predictive of b-DFS at 4 years. Only DMFS was worse for the VHR group for both pre and

Table 2 Sites of Recurrence

\begin{tabular}{llll}
\hline 0 & 173 & 85.2 & \\
\hline Biochemical failure & 4 & 2 & 2 \\
M1a & 3 & 1.5 & 4 \\
M1b & 16 & 7.9 & 1 \\
M1c & 6 & 3 & 1 \\
Local & 1 & 0.5 & \\
\hline
\end{tabular}

$\mathrm{M} 1 \mathrm{a}=$ non regional lymph nodes, $\mathrm{M} 1 \mathrm{~b}=$ bones, $\mathrm{M} 1 \mathrm{c}=$ visceral When several sites of recurrence were present, the most advanced category was used post revision NCCN definitions $(p=.03$ and .01 respectively). This difference was not observed if upstaging using $\geq 2$ HR factors was applied and this effect did not persevere on MVA. Cox univariate analysis was also significant for: PSA $\geq 40 p=0.001$; clinical stages T2c $p=.004$, T3b $p=.02$ and $>4$ cores with Gleason $8-10 p<.03$.

On MVA, PSA $\geq 40 \mathrm{ng} / \mathrm{ml}$ was the only significant predictor of b-DFS or DMFS at 4 years with a HR of 3.75 and 3.25, $p<0.005$ (Table 4). KM estimates for PSA above and below $40 \mathrm{ng} / \mathrm{ml}$ are shown in Figs. 1a and b.

Treatment was well tolerated with significant late $\geq$ grade $3 \mathrm{GU}$ toxicity of $10 \%$ which was predominantly due to reports of nocturia more than 5 times per night. Late $\geq$ grade 3 GI toxicity of $3.5 \%$ was due to rectal bleeding (Table 5).

\section{Discussion}

This study supports the assertion that patients with both HR and VHR prostate cancer treated with high dose CRT, PLNRT and ADT have favorable outcomes with low toxicity. The use of dose escalation, CRT, PLNRT, image guidance and ADT have all been associated with improved outcomes or reduced toxicity [11-15] and the results of this study are consistent with favorable outcomes reported from studies that used CRT with ADT to treat patients with HR disease [16]. While our results are encouraging, these findings must be interpreted cautiously since longer follow-up time is needed to verify our findings.

Dissimilarities in risk factors and co-morbidities of $\mathrm{HR}$ patients treated with RP or CRT make comparison of outcomes between surgical and radiation treatments unreliable. Series reporting treatment outcomes for CRT with HR disease include many patients with advanced disease or comorbidities that would exclude consideration for RP. Despite the inclusion of patients with adverse risk factors, our results compare well to outcomes reported for $\mathrm{HR}$ patients treated with $\mathrm{RP}[2,17,18]$. Furthermore, we report low rates of acute and late GI and GU toxicity that are consistent with other CRT series [19]. In contrast, HR patients treated with RP often require adjuvant or salvage $\mathrm{RT}$ which is associated with increased toxicity when compared to treatment with RP or RT alone [20, 21].

The 2015 revisions to the VHR subgroup were based on the findings of Sundi et al. who reviewed prognostic factors and outcomes from a surgical series of 753 men with HR prostate cancer to create risk factor groupings predictive for metastatic disease and prostate cancer specific mortality [4]. Based on Sundi's findings, the revised 2015 NCCN guidelines added two additional criteria for inclusion of HR patients into the VHR subgroup $[1,4]$. When subdividing our CRT series into HR/ VHR subgroupings, we observed that stage migration 
Table 3 Patient distribution by NCCN HR and VHR risk groups and 4 year b-DFS, MFS, CSS and OS

\begin{tabular}{|c|c|c|c|c|c|c|c|c|}
\hline & 2014 & & $2014+>2 H R$ & & 2015 & & $2015+>2 \mathrm{H}$ & \\
\hline & $\mathrm{HR}$ & $\mathrm{VHR}$ & $\mathrm{HR}$ & $\mathrm{VHR}$ & $\mathrm{HR}$ & $\mathrm{VHR}$ & $\mathrm{HR}$ & $\mathrm{VHR}$ \\
\hline N & 166 & 37 & 131 & 72 & 100 & 103 & 65 & 138 \\
\hline$\%$ & $82 \%$ & $18 \%$ & $64.5 \%$ & $35.5 \%$ & $49 \%$ & $51 \%$ & $32 \%$ & $68 \%$ \\
\hline $4 y$ bDFS \% $(95 \%$ Cl) & 89 (82-93) & $83(66-92)$ & 89 (82-93) & $84(73-91)$ & $90(82-95)$ & $85(75-91)$ & $92(80-97)$ & $85(78-90)$ \\
\hline 4y MFS \% (95\% Cl) & $90(84-94)$ & $83(63-93)$ & 92 (84-96) & $85(72-92)$ & $93(85-97)$ & $85(75-92)$ & 93 (78-98) & $87(80-92)$ \\
\hline $4 y$ CSS \% $(95 \%$ Cl) & 100 & $92(70-98)$ & 100 & 95 (82-99) & 100 & 97 (88-99) & 100 & $98(91-99)$ \\
\hline $4 y$ OS $\%(95 \%$ Cl) & 96 (92-99) & 85 (64-94) & $98(93-100)$ & 87 (74-94) & 96 (89-99) & $92(83-96)$ & 100 & $91(84-96$ \\
\hline
\end{tabular}

$\mathrm{HR}=$ High Risk, VHR = Very High Risk, b-DFS = biochemical disease free survival, MFS = metastasis free survival, CSS = cause specific survival, OS = overall survival NCCN 2014 HR= Stage: T3a, Gleason: 8-10, PSA $>20, V H R=T 3 B, T 4$

NCCN 2015 HR= Stage: T3a, Gleason: 8-10, PSA>20, T3b-T4, Primary Gl 5, >4 cores with Gl 8-10

was substantial. The percentage of patients considered VHR increased from 18 to $62 \%$ as the number of criteria considered for inclusion in the VHR subgroup increased. We suggest that redistribution of patients into the VHR group may improve the reliability of comparisons of $\mathrm{HR}$

Table 4 Univariate and Multivariate Survival Analysis

\begin{tabular}{|c|c|c|c|c|}
\hline \multirow[t]{2}{*}{ Variable } & \multicolumn{2}{|c|}{ Univariate analysis } & \multicolumn{2}{|c|}{ Multivariate analysis } \\
\hline & $P$-value & HR $(95 \% \mathrm{Cl})$ & $P$-value & $\mathrm{HR}(95 \% \mathrm{Cl})$ \\
\hline \multicolumn{5}{|l|}{ Clinical stage } \\
\hline $\mathrm{T} 1-\mathrm{T} 2 \mathrm{a}$ & - & 1.0 (reference) & - & - \\
\hline $\mathrm{T} 2 \mathrm{~b}-\mathrm{c}$ & 0.162 & $2.51(0.69-9.16)$ & - & - \\
\hline Т3а & 0.227 & $2.23(0.6-8.28)$ & - & - \\
\hline T3b-T4 & 0.045 & $3.91(1.02-14.86)$ & 0.138 & $1.33(0.91-1.93)$ \\
\hline \multicolumn{5}{|l|}{ Gleason score } \\
\hline$\leq 6$ & - & 1.0 (reference) & - & - \\
\hline 7 & 0.223 & $3.65(0.45-29.42)$ & - & - \\
\hline $8-10$ & 0.34 & $2.66(0.35-19.87)$ & - & - \\
\hline \multicolumn{5}{|l|}{ PSA } \\
\hline$<40$ & - & 1.0 (reference) & - & - \\
\hline$\geq 40$ & $<0.001$ & $3.84(1.82-8.080$ & 0.001 & $3.75(1.76-7.97)$ \\
\hline \multicolumn{5}{|c|}{$>4$ cores positive with Gleason 8-10 } \\
\hline$\leq 4$ & - & 1.0 (reference) & - & - \\
\hline$>4$ & 0.032 & $2.27(1.07-4.8)$ & 0.23 & $1.41(0.8-2.51)$ \\
\hline Unknown & 0.635 & $0.6(0.07-4.7)$ & - & - \\
\hline \multicolumn{5}{|c|}{ Primary Gleason pattern } \\
\hline$<5$ & - & 1.0 (reference) & - & - \\
\hline 5 & 0.124 & $2.12(0.81-5.55)$ & - & - \\
\hline \multicolumn{5}{|l|}{ NCCN risk } \\
\hline High risk & - & 1.0 (reference) & - & - \\
\hline VHR & 0.07 & $1.99(0.94-4.23)$ & - & - \\
\hline \multicolumn{5}{|l|}{ RT technique } \\
\hline $3 D$ & - & 1.0 (reference) & - & - \\
\hline IMRT & 0.392 & $1.57(0.55-4.41)$ & - & - \\
\hline VMAT & 0.376 & $1.67(0.53-5.22)$ & - & - \\
\hline
\end{tabular}

patients treated primarily with surgery versus those treated with radiation.

We found that patients treated with high dose CRT and ADT did well irrespective of current HR/VHR classification and that PSA $\geq 40 \mathrm{ng} / \mathrm{ml}$ was the best discriminator of poor outcomes. In contrast to our findings, Narang et al. showed that when evaluating patients with HR disease who were treated over a 15 year interval from 1993 to 2006, the revised 2015 NCCN HR/VHR subgrouping were predictive for worse outcomes in the VHR subgroup [6]. Although the long follow-up interval is an important strength of Narang's study, the median follow-up time of our cohort is $50 \mathrm{~m}$ (range: $12 \mathrm{~m}-142 \mathrm{~m}$ ) and the median time to BF in our reports are similar at $34 \mathrm{~m}$ and $30 \mathrm{~m}$. The difference in our findings may be better explained by the differences in treatment received by our respective cohorts. Narang reported the use of a diverse assortment of radiation techniques with a mean dose of 70.2 Gy (range: 64.8-75.6 Gy), and differing ADT protocols. Narang was unable to demonstrate improvement in failure endpoints with dose escalation over 72Gy although use of neo-adjuvant ADT was associated with reduced $\mathrm{BF}$ and DMFS. In comparison, the patients in our series received uniform CRT with a minimum dose of 78 Gy (range: $78-82$ Gy), PLNRT, and ADT that is reflective of current practice. Increased radiation dose and use of ADT have been shown to be associated with improved b-DFS and DMFS [11, 22, 23]. Pollack et al. in a randomized trial showed that doses $<78 \mathrm{~Gy}$ versus $\geq 78$ Gy were associated with improved b-DFS and DMFS and Denham et al. reported that both dose escalation and increased duration of ADT reduced local progression and BF [22, 23].

The only risk factor predictive for reduced b-DFS or DMFS on MVA in our series was PSA $\geq 40 \mathrm{ng} / \mathrm{ml}$. This finding is consistent with other studies showing elevated PSA at time of diagnosis to be highly predictive for metastatic disease following either RT or RP [24-27]. These findings suggest that future modifications to the NCCN guidelines consider PSA level as a criteria for 

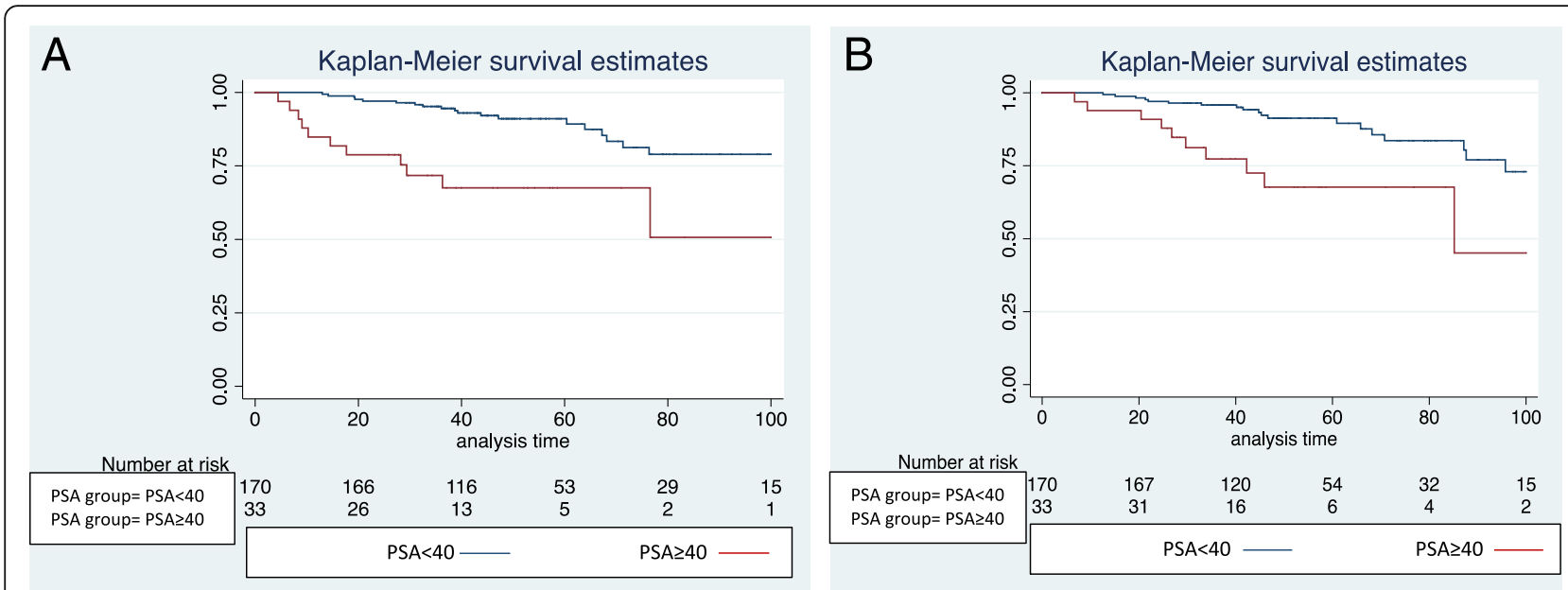

Fig. 1 a and b KM Survival Estimate Stratified by PSA $\geq 40 \mathrm{ng} / \mathrm{ml},<40 \mathrm{ng} / \mathrm{ml}$ showing Biochemical Disease Free Survival (Fig. 1a) and Metastasis Free Survival (Fig. 1b)

inclusion into the VHR group. We caution that elevated PSA should not be used as an exclusion criteria for definitive treatment since many patients with elevated PSA may benefit from definitive therapy [24].

Patterns of failure analysis shows that distant failure was dominant and isolated initial failure within the lymph nodes, prostate or as BF alone was uncommon. The use of functional imaging has allowed us to identify sites of distant failure early which decreased the number of patients considered LR or BF alone. In contrast to our findings, several studies which used bone scan, CT and prostate biopsy to evaluate patients with BF have reported that the prostate is the most common first site of failure following RT for HR patients [28, 29]. Although prostate biopsy results were not available in our series, choline PET-CT and endorectal-MRI imaging in patients with BF allowed for early detection of metastatic disease in most patients. These findings support the use of CRT with ADT to treat patients with HR disease and suggest that further intensification of local therapy will provide little benefit for HR patients and may only add morbidity. [2, 3, 17, 30, 31].

The NCCN guidelines were revised in 2014 to include choline PET-CT imaging of patients with BF for consideration of focal salvage therapy [32]. Early adaptation of

Table 5 Toxicity Profile

\begin{tabular}{llllll}
\hline & Gl toxicity & & & GU toxicity & \\
\cline { 2 - 3 } & Acute $(\%)$ & Late $(\%)$ & & Acute $(\%)$ & Late $(\%)$ \\
\hline Grade 0 & $140(69 \%)$ & $166(82 \%)$ & & $53(26 \%)$ & $117(58 \%)$ \\
Grade 1 & $58(29 \%)$ & $17(8 \%)$ & & $112(55 \%)$ & $31(15 \%)$ \\
Grade 2 & $3(1.5 \%)$ & $13(6.4 \%)$ & & $32(16 \%)$ & $34(17 \%)$ \\
Grade 3 & $2(1 \%)$ & $7(3.5 \%)$ & & $6(3 \%)$ & $21(10 \%)$ \\
Grade 4 & - & - & - & - \\
\hline
\end{tabular}

functional imaging with choline PET-CT allowed us to offer patients with local failure or oligo-metastatic disease salvage treatment using targeted radiation therapy and avoid early administration of ADT [8]. Extending the use of functional imaging agents for use during initial staging may further improve outcomes with RP and CRT by identifying and excluding patients with early metastatic disease from receiving definitive therapy.

The absence of a central pathology review is an important study limitation. Since patients were referred from several different institutions, variation between pathologists in assigning Gleason grades to the biopsy specimens may have affected the classification of our patients into HR and VHR subgroups. Although several different CRT treatment techniques were used during the study period and moderate hypo-fractionation and IGRT were instituted only after 2009, univariate and multivariate analysis were unable to demonstrate differences in outcome based on treatment technique. Although most BFs occur within 5 years of treatment [33], longer duration of follow-up is needed to verify our findings.

\section{Conclusions}

Prostate cancer patients with HR and VHR disease achieve excellent LC and DMFS with low toxicity when treated with dose escalated CRT, PLNRT and ADT. Reclassification of HR patients into HR/VHR subgroups using original or revised NCCN criteria had no impact on treatment outcomes. Only PSA $\geq 40 \mathrm{ng} / \mathrm{ml}$ was associated with poor prognosis. The use of functional imaging to evaluate BF showed that distant failure was dominant and LR in the prostate rare, challenging the notion that intensification of local therapy will further improve outcomes. Further study and longer follow-up is required to validate these findings. 


\section{Abbreviations}

ADT: Androgen Deprivation Therapy; B-DFS: Biochemical Disease Free Survival; BF: Biochemical Failure; BR: Biochemical Recurrence; Cl: Confidence Interval; CRT: Conformal Radiation Therapy; CTV: Clinical Target Volume; GI: Gastrointestinal; GU: Genitourinary; HR: Hazard Ratio; HR: High Risk; IGRT: Image Guided Radiation Therapy; IMRT: Intensity Modulated Radiation Therapy; KM: Kaplan Meier; LR: Local Recurrence; M: Months; MFS: Metastasis Free Survival; MVA: Multivariate Analysis; NCCN: National Comprehensive Cancer Network; OS: Overall Survival; PCSS: Prostate Cancer Specific Survival; PLNRT: Pelvic Lymph Node Radiation Therapy; PSA: Prostate Serum Antigen; PTV: Planning Target Volume; RP: Radical Prostatectomy; RT: Radiation Therapy; VHR: Very High Risk; VMAT: Volume Modulated Radiation Therapy

\section{Acknowledgements}

Authors wish to thank the Parasol Foundation and the LeRoy Schecter Foundation for providing support for this study and Gavin Urban MBBS, for providing assistance with statistical analysis.

\section{Funding}

This study was funded in part by unrestricted grants to the Sheba Radiation Oncology Department from the Parasol Foundation and the LeRoy Schecter Foundation.

\section{Availability of data and materials}

The dataset supporting the conclusions of this article are included within the article.

\section{Authors' contributions}

$\mathrm{AS}, \mathrm{JG}$, and $\mathrm{ZS}$ contributed equally to the conception and design of the study, analysis and interpretation of data and drafting and revising the final manuscript and share equally as senior authors in the study. YRL and BS participated in the conception and study design, data interpretation and manuscript review and revision. RL-A, RB, and DU contributed to acquisition and interpretation of data and manuscript revision. TD contributed to conception of study, acquisition and interpretation of data, and preparation and revision of manuscript. LT, DA, and IW were responsible for acquisition, interpretation and analysis of data. All authors have review and approved the final version of the manuscript.

\section{Competing interests}

The authors have no conflicts of interest to report.

\section{Consent for publication}

Not applicable.

\section{Ethics approva}

This study was conducted from data taken from a Department of Radiation Oncology, Prostate Cancer prospective database that was approved by the Sheba Medical Center, Ethics Committee. All research and record review was done in accordance with the Declaration of Helsinki.

\section{Author details}

'Departments of Radiation Oncology, Chaim Sheba Medical Center, Tel Aviv University Sackler School of Medicine, Tel Hashomer, 52621 Ramat Gan, Israel. ${ }^{2}$ Medical Oncology, Chaim Sheba Medical Center, Tel Aviv University Sackler School of Medicine, Tel-Hashomer 52621, Israel. ${ }^{3}$ Nuclear Medicine, Chaim Sheba Medical Center, Tel Aviv University Sackler School of Medicine, Tel-Hashomer 52621, Israel.

Received: 24 June 2016 Accepted: 12 December 2016

Published online: 06 January 2017

\section{References}

1. Mohler JL, Kantoff PW, Armstrong AJ, Bahnson RR, Cohen M, D'Amico AV, et al. Prostate cancer, version 2.2014. J Natl Compr Canc Netw. 2014;12(5):686-718.

2. Stewart SB, Boorjian SA. Radical prostatectomy in high-risk and locally advanced prostate cancer: Mayo Clinic perspective. Urol Oncol. 2014; 33:235-44.

3. Soares R, Eden CG. Surgical treatment of high risk prostate cancer. Minerva Urol Nefrol. 2014;67(1):33-46.
4. Sundi D, Wang VM, Pierorazio PM, Han M, Bivalacqua TJ, Ball MW, et al. Very-high-risk localized prostate cancer: definition and outcomes. Prostate Cancer Prostatic Dis. 2014;17(1):57-63.

5. Sundi D, Wang V, Pierorazio PM, Han M, Partin AW, Tran PT, et al. Identification of men with the highest risk of early disease recurrence after radical prostatectomy. Prostate. 2014;74(6):628-36.

6. Narang AK, Gergis C, Robertson SP, He P, Ram AN, McNutt TR, et al. Very High-Risk Localized Prostate Cancer: Outcomes Following Definitive Radiation. Int J Radiat Oncol Biol Phys. 2016;94(2):254-62.

7. Saad A, Goldstein J, Lawrence YR, Weiss I, Saad R, Spieler B, et al. Transperineal implantation of gold fiducial markers (gold seeds) for prostate image-guided radiation therapy: a feasible technique associated with a low risk of complications. J Med Radiat Sci. 2015;62(4):261-6.

8. Goldstein J, Even-Sapir E, Ben-Haim S, Saad A, Spieler B, Davidson T, Berger R, Weiss I, Appel S, Lawrence YR, Symon Z. Does Choline PET/CT Change the Management of Prostate Cancer Patients With Biochemical Failure? Am J Clin Oncol. 2014. [Epub ahead of print] PubMed PMID: 25319322

9. Roach 3rd M, Hanks G, Thames Jr H, Schellhammer P, Shipley WU, Sokol GH, et al. Defining biochemical failure following radiotherapy with or without hormonal therapy in men with clinically localized prostate cancer: recommendations of the RTOG-ASTRO Phoenix Consensus Conference. Int J Radiat Oncol Biol Phys. 2006;65(4):965-74.

10. National Cancer Institute. Common Terminology Criteria for Adverse Events v4.0. NCl, NIH, DHHS. May 29, 2009. NIH publication \# 09-7473.

11. Zelefsky MJ, Pei X, Chou JF, Schechter M, Kollmeier M, Cox B, et al. Dose escalation for prostate cancer radiotherapy: predictors of long-term biochemical tumor control and distant metastases-free survival outcomes. Eur Urol. 2011;60(6):1133-9.

12. Pahlajani N, Ruth KJ, Buyyounouski MK, Chen DY, Horwitz EM, Hanks GE, et al. Radiotherapy doses of $80 \mathrm{~Gy}$ and higher are associated with lower mortality in men with Gleason score 8 to 10 prostate cancer. Int J Radiat Oncol Biol Phys. 2012;82(5):1949-56.

13. Lawton CA, DeSilvio M, Roach 3rd M, Uhl V, Kirsch R, Seider M, et al. An update of the phase III trial comparing whole pelvic to prostate only radiotherapy and neoadjuvant to adjuvant total androgen suppression: updated analysis of RTOG 94-13, with emphasis on unexpected hormone/ radiation interactions. Int J Radiat Oncol Biol Phys. 2007;69(3):646-55.

14. Bolla M, Van Tienhoven G, Warde P, Dubois JB, Mirimanoff RO, Storme G, et al. External irradiation with or without long-term androgen suppression for prostate cancer with high metastatic risk: 10-year results of an EORTC randomised study. Lancet Oncol. 2010;11(11):1066-73.

15. Kaidar-Person O, Roach 3rd M, Crehange G. Whole-pelvic nodal radiation therapy in the context of hypofractionation for high-risk prostate cancer patients: a step forward. Int J Radiat Oncol Biol Phys. 2013;86(4):600-5.

16. Stenmark MH, Blas K, Halverson S, Sandler HM, Feng FY, Hamstra DA. Continued benefit to androgen deprivation therapy for prostate cancer patients treated with dose-escalated radiation therapy across multiple definitions of high-risk disease. Int J Radiat Oncol Biol Phys. 2011;81(4):e33544.

17. Moltzahn F, Karnes J, Gontero P, Kneitz B, Tombal B, Bader P, et al. Predicting prostate cancer-specific outcome after radical prostatectomy among men with very high-risk cT3b/4 PCa: a multi-institutional outcome study of 266 patients. Prostate Cancer Prostatic Dis. 2015;18(1):31-7.

18. Abdollah F, Sood A, Sammon JD, Hsu L, Beyer B, Moschini M, et al. Long-term Cancer Control Outcomes in Patients with Clinically High-risk Prostate Cancer Treated with Robot-assisted Radical Prostatectomy: Results from a Multi-institutional Study of 1100 Patients. Eur Urol. 2015;68(3):497-505.

19. Spratt DE, Pei X, Yamada J, Kollmeier MA, Cox B, Zelefsky MJ. Long-term survival and toxicity in patients treated with high-dose intensity modulated radiation therapy for localized prostate cancer. Int J Radiat Oncol Biol Phys. 2013;85(3):686-92

20. Cozzarini C, Fiorino C, Da Pozzo LF, Alongi F, Berardi G, Bolognesi A, et al. Clinical factors predicting late severe urinary toxicity after postoperative radiotherapy for prostate carcinoma: a single-institute analysis of 742 patients. Int J Radiat Oncol Biol Phys. 2012;82(1):191-9.

21. Perna L, Alongi F, Fiorino C, Broggi S, Cattaneo Giovanni M, Cozzarini C, et al. Predictors of acute bowel toxicity in patients treated with IMRT whole pelvis irradiation after prostatectomy. Radiother Oncol. 2010:97(1):71-5.

22. Pollack A, Zagars GK, Starkschall G, Antolak JA, Lee JJ, Huang E, et al. Prostate cancer radiation dose response: results of the M. D. Anderson phase III randomized trial. Int J Radiat Oncol Biol Phys. 2002;53(5):1097-105. 
23. Denham JW, Steigler A, Joseph D, Lamb DS, Spry NA, Duchesne G, et al. Radiation dose escalation or longer androgen suppression for locally advanced prostate cancer? Data from the TROG 03.04 RADAR trial. Radiother Oncol. 2015;115(3):301-7.

24. Lawrence YR, Samueli B, Levitin R, Pail O, Spieler B, Pfeffer R, Goldstein J, Den RB, Symon Z. Do Prostate Cancer Patients With Markedly Elevated PSA Benefit From Radiation Therapy?: A Population-based Study. Am J Clin Oncol. 2015. [Epub ahead of print] PubMed PMID: 26125304.

25. Alexander A. Extreme-risk Prostate Adenocarcinoma Presenting with Prostate-specific Antigen (PSA) $>40 \mathrm{ng} / \mathrm{ml}$ : Prognostic Significance of the Preradiation PSA Nadir. Int J Radiat Oncol Biol Phys. 2011:81(5):e713-9.

26. Rodrigues G, Bae K, Roach M, Lawton C, Donnelly B, Grignon D, et al. Impact of ultrahigh baseline PSA levels on biochemical and clinical outcomes in two Radiation Therapy Oncology Group prostate clinical trials. Int J Radiat Oncol Biol Phys. 2011:80(2):445-52

27. Gontero P, Spahn M, Tombal B, Bader P, Hsu CY, Marchioro G, et al. Is there a prostate-specific antigen upper limit for radical prostatectomy? BJU Int. 2011;108(7):1093-100.

28. Jalloh M, Leapman MS, Cowan JE, Shinohara K, Greene KL, Roach 3rd M, et al. Patterns of Local Failure following Radiation Therapy for Prostate Cancer. J Urol. 2015;194(4):977-82.

29. Zumsteg ZS, Spratt DE, Romesser PB, Pei X, Zhang Z, Kollmeier M, et al. Anatomical Patterns of Recurrence Following Biochemical Relapse in the Dose Escalation Era for Prostate Patients Undergoing External Beam Radiotherapy. J Urol. 2015;194(6):1624-30.

30. Koontz BF, Quaranta BP, Pura JA, Lee WR, Vujaskovic Z, Gerber L, et al. Phase 1 trial of neoadjuvant radiation therapy before prostatectomy for high-risk prostate cancer. Int J Radiat Oncol Biol Phys. 2013;87(1):88-93.

31. Oderda M, Joniau S, Spahn M, Gontero P. Debulking surgery in the setting of very high-risk prostate cancer scenarios. BJU Int. 2012;110(6 Pt B):E192-8.

32. Mohler JL, Kantoff PW, Armstrong AJ, Bahnson RR, Cohen M, D'Amico AV, et al. Prostate cancer, version 1.2014. J Natl Compr Canc Netw. 2013:11(12):1471-9.

33. Nguyen T, Boldt RG, Rodrigues G. Prognostic Factors for Prostate Cancer Endpoints Following Biochemical Failure: A Review of the Literature. Cureus. 2015;7(1):e238.

\section{Submit your next manuscript to BioMed Central and we will help you at every step:}

- We accept pre-submission inquiries

- Our selector tool helps you to find the most relevant journal

- We provide round the clock customer support

- Convenient online submission

- Thorough peer review

- Inclusion in PubMed and all major indexing services

- Maximum visibility for your research

Submit your manuscript at www.biomedcentral.com/submit

) Biomed Central 